\title{
The Inclusion of Children with Autism Spectrum Disorder in Mainstream School: Views of Special Education Teachers
}

\author{
Aristotelou Afroditi \\ Special Education Teacher, University of Patras, Patras, Greece \\ Email: aaristotelous@yahoo.gr
}

How to cite this paper: Afroditi, A. (2021) The Inclusion of Children with Autism Spectrum Disorder in Mainstream School: Views of Special Education Teachers. Open Access Library Journal, 8: e8132. https://doi.org/10.4236/oalib.1108132

Received: October 29, 2021

Accepted: November 27, 2021

Published: November 30, 2021

Copyright $\odot 2021$ by author(s) and Open Access Library Inc.

This work is licensed under the Creative Commons Attribution International License (CC BY 4.0).

http://creativecommons.org/licenses/by/4.0/ (c) (i) Open Access

\begin{abstract}
Children with Autism Spectrum Disorder, when interacting with people in their immediate environment (such as other family members, classmates, educators, therapists), have difficulty in understanding the position of other people so that they can react appropriately. This is related to the difficulty these children face, which is recognizing and understanding the feelings of other people around them. The ever-increasing use of technology in education could be combined with the emotional development of children with Autism Spectrum Disorder, as it offers a variety of visual stimuli, which contributes positively to the learning of these children. The aim of the present study was to collect research data on the views of Special Educators and Therapists on their observation of specific behaviors developed by students with Autism Spectrum Disorder. The sample consisted of two hundred and fifty-six (256) Special Educators and Therapists, including as factors their demographic and professional characteristics. A quantitative approach and a thoroughly structured questionnaire were used as a tool for data collection to explore these views. The results of the research process demonstrate the attitude of experts towards the inclusion of children with Autism Spectrum Disorder in the general school, as well as argue that these children can generalize the ability to understand emotions. However, some factors, such as the lack of specialized technological equipment, the lack of training of teachers on the treatment of students with ASD, the financial data of parents who do not allow students to enroll in a special school, act as obstacles in the educational process. It is understood that education is particularly effective for the development of communication skills of students with Autism Spectrum Disorder, for their socialization, for the improvement of their behavior inside and outside the classroom. On the part of educators and therapists, positive views are expressed about the effectiveness of education in the general school of stu-
\end{abstract}


dents with Autism Spectrum Disorder.

\section{Subject Areas}

Special Education

\section{Keywords}

Inclusion, Autism, Special Education Teachers, Mainstream School Teachers, Integration

\section{Introduction}

In children with autistic disorders, in most cases, a small degree of socialization is identified, while they are excluded from many social contexts due to the problem they face. In this social context, the question of whether these children can be included in the general school is included. When this happens, the social skills of children with autism are improved [1]. One of the main goals of the inclusion of children with autistic disorders in general school is non-social exclusion, which means that some people are isolated from the public with the contribution of disability from others, due to lack of skills or low financial status or due to some special needs that result in obvious discrimination. Their non-participation is not only included in the commons, but also in the opportunities for work, for education, for sports and artistic activities, for entertainment, for their equal service in services etc. [2]. Through the general school, equal opportunities can be achieved, i.e. the ability of each person to be included and enjoy the opportunities, on the same basis as all other people [3]. Clearly, there are certain conditions for a child with autism to enroll in a general school, such as having a special educator. According to Exarchou [4] research, several scientists argue that children with Autism Spectrum Disorder should be included and co-educated in the general grades of a school, along with children of normal development. Teachers are now called upon to work with special educators to ensure that the child with autism has the best possible performance in the lessons.

The difficult part of adapting these children to a normal school environment focuses on the fact that they are accustomed to being guided by their parents and find it difficult to build relationships and develop joint activities with people of the same age [5]. More specifically, children with ASD in the field of social development present difficulties both in interpersonal relationships with their peers and in their social transactions [6]. By offering solutions to students with autistic disorders such as the specialist educator, the child psychologist, access to technological means, the result is an increase in their degree of socialization, while the feeling of diversity and the solution of isolation are eliminated [7] [8].

Self-management of emotions and actions, for children with autistic disorders, you consider a very important process but at the same time necessary for the 
child, initially, to feel that he is functioning autonomously and consequently to be easier to integrate in school [9]. The difficulties faced by children with ASD are in emotional and social understanding as well as in cognitive development, both in communication and in their behavior [10]. In the emotional field of children, however, there is either apathy due to the lack of empathy of these children or they show an excessive reaction to the stimuli received from their environment [1]. The relationships that exist between the people in the familiar environment of the child, directly affect the behavior of the autistic child at school. When there is a child with any form of disability, relationships are shaken, as well as the role of each member in the family. Conflicts and tensions become less intense when the child's psychological support is gradually "built" in order to understand that he is entitled to equal opportunities [11]. As a result of this method, comes the normalization of family relationships. One of the biggest mistakes parents make is the frustration they feel about themselves, considering it their own fault. You observe this phenomenon mainly in single-parent families, while frustration, combined with the parent's refusal for psychological support and lack of knowledge, results in the non-socialization of the child and his complete isolation [11]. Among the models that are followed, for many consecutive years by psychologists and bring results in the psychosynthesis of parents with children of any kind of dysfunction, is the Stage Model [12] [13]. Parents' discussions with the psychologist focus on their feelings that were created from the moment the problem was realized. In the next step, the expert asks the parents to categorize their feelings into intense and less intense, as well as their reactions when they are with the child for a long time. Each parent observes the other's behaviors, but without developing characterizations to achieve the ultimate goal of accepting the child and alternative ways to provide equal support and assistance from all family members [12] [13].

The benefits through group activities in a school environment are found in improving the physical health of these children, their mental health but these benefits are also found in other children who accept their peers with this difference [14].

Even from a legal point of view, according to Article 7 of the Greek Constitution "the best interests of the child shall be a primary consideration for all activities involving children with any form of disability" (http://www.un.org). Law 3699/2008 [15] on "Special Education and Training of Persons with Disabilities or Special Educational Needs" has also been enacted. The avant-garde of this law is in the concept of Special Auxiliary Personnel (SUP) but also in the strengthening of the institution of parallel support [16].

Thus, through the inclusion of children with autism in the general school, participatory education is developed. Which means that there are no restrictions on education, while providing quality education for all students with respect for diversity and different needs and abilities, characteristics and learning of students' expectations, eliminating any discrimination. Co-education is a process of 
enhancing the capacity of the education system so that all students receive knowledge. Education is a basic human right and the foundation for a society that wants to be fair, equitable and truly developed (http://unesdoc.unesco.org/images/0017/001778/177849e.pdf).

\section{Theoretical Framework}

It is considered very important, before moving on to the conceptual approach of autistic disorders, to note that autism is defined as a highly diffuse or universal developmental disorder that usually appears before the child reaches the age of three [17]. Numerous conceptual approaches have been attributed to autistic disorders, among them, as a set of various manifestations of the same disorder, from the most severe to the mildest, where there is a lower IQ and other cognitive characteristics [18]. Another conceptual approach to autistic disorders is given as the repetition of a child's movements, sounds, expressions, combined with an explosive behavior when there is a remodeling in the space. The first definition was given, in part, as strict as autistic disorders were defined as the inability of a child to adapt to other people, while they are characterized by the feeling of satisfaction when isolated and focused only on parents [19]. Another conceptual approach to autistic disorders is the abnormal physical-mental-spiritual development of a person with underdeveloped communication skills and socialization problems [20] [21].

However, there is also Asperger's Syndrome, according to which the characteristic peculiarity of the gaze is obvious to the child and in particular the absence of eye contact, while they seem to perceive things only with a sideways gaze and never with a straight one. Personal expressions as well as gestures are inadequate and limited, while movements are stereotyped and impulsive. In this Syndrome, there is also a refusal of children to learn and cooperate with educators, as well as a negative relationship with other family members. Finally, you observe the invention of words and the way of thinking without any coherence [22] [23].

The samples that show that a child has autistic disorders, are revealed in the first three years of his life, while in many cases from the first period of 18 months [24]. There are a few cases where autistic disorders were caused in old age in the child and were the result of an infectious disease. The first signs that are identified from the moment of birth (and parents may not realize it, but pediatricians are aware of these signs) are the gaze that focuses for a long time on a point [24] [25], disgust and denial to the care of the mother and excessive restless sleep [26]. Some other signs that are related exclusively to the behavior are the intense mood swing of a child such as e.g. the abrupt change of a cheerful and social behavior in isolation and self-destruction [26]. Some other examples of autistic disorder in children and not in infants are hoarseness, refusal to socialize, especially with people of the same age, incoherent expressions and time delay in speech, hyperactivity, reaction to any change, or not, knowledge of handling any object and ignorance of the risk [26]. What makes it difficult for 
children with autistic disorders to develop relationships with other people is the inability to separate emotions, movements, so-called. A verbal expression or a facial expression, which by two people used differently, for these children there is no difference in the way, they perceive both cases the same. The most difficult and dangerous part, both for the children themselves and for the rest of their family members, are the cases of self-injury [27].

For many years, specific internationally recognized diagnostic criteria for autistic disorders have been used. Thus, according to the Diagnostic and Statistical Manual (DSM -// IR), of the American Psychiatric Society, the diagnostic criteria are [28] [29]: autistic loneliness which means lack of awareness of the existence of other people and their feelings, the lack of seeking attention, consolation, love and all tender feelings, zero behavior in initiating movements, avoiding group games and the constant refusal to socialize with peers inside and outside the school environment. The qualitative deviation in the written and oral speech and in the creative activity. The development of oral speech occurs very rarely, especially when the child is in preschool age and is not provided with any special help by qualified educators, while facial expressions are noted in rare cases. In addition, the child's intolerance to spontaneous behaviors of other people towards the same as e.g. the zero reaction in a hug. The elliptical ability to create a game with fantasy heroes or create a fantasy story. Clear anomalies in the form of speech content that include stereotypical and repetitive use of speech, coding of words and expressions, and comments on any topic other than the one under discussion. The limited range of activities. This includes stereotyped and abnormal movements, long-term involvement with an object, and creates great panic in the child when any change occurs in the space he is in [28] [29].

According to the DSM-IV, the diagnostic criteria for Autistic Disorder fall into three categories: social behavior, communication, and deviant behavior. When a child has more than six characteristics, at least two of them should be related to the category of social behavior, one related to the ability to communicate, as well as one to the deviant behavior. The result of the diagnosis then is, without a doubt, autism [1]. The fifth edition of the DSM [30], released in May 2013 , brought many changes to the diagnostic criteria for autism. One of them is located in the conceptual approach "Diffuse Developmental Disorders" which was replaced by the concept of "Autism Spectrum Disorder" (ASD) [28] [31]. Level 1 includes people who find it difficult to be flexible and communicate with other people but never have difficulty socializing. Level 2 includes people who face difficulties in socializing and flexibility, but not in developing communication. Level 3 categorizes people in need of enhanced support, i.e. people who face daily difficulties in communication and socialization process, but never in flexibility [32].

Decades ago, it was claimed by medical scientists that the only cause was emotional disorders, which is now being debunked and one of the reasons is that about a third of autistic adolescents have seizures all of a sudden. Some research 
shows that it is a neurological problem that affects the parts of the brain that are associated with language and the ability to develop speech. However, to some extent, autistic disorders are associated with genetic reasons (3\% - 5\%) and not individually by the mother but also by both parents [20] [33]. The difficult part of adapting these children to a normal school environment focuses on the fact that they are accustomed to being guided by their parents and find it difficult to build relationships and develop joint activities with people of the same age [5]. More specifically, children with ASD in the field of social development present difficulties both in interpersonal relationships with their peers and in their social transactions [1]. Offering students with autistic disorders, solutions such as the special educator, the child psychologist, access to technological means, the result is an increase in their degree of socialization, while the feeling of diversity and the solution of isolation, are eliminated [7] [8].

Regarding the duration of the pregnancy, there are cases where the fetuses were affected by an illness that the mother went through, as a result of which they are noted. Also, the administration of the triple vaccine (MMR measles, mumps, rubella), creates irritable bowel syndrome in combination with inability to communicate, aggressive behaviors, zero degree of socialization, in children older than infancy (2 - 3 years) [34].

According to the studies of the last 30 years, there is an increase in the birth rates of children with Autism Spectrum Disorders, a fact that is quite worrying, while in the scale of the most severe disabilities, it ranks second and by $90 \%$, it appears in combination with other disabilities [17]. According to demographic research findings for Autism Spectrum Disorder, children with autism did not exist in families of high socio-economic status, as the initial perceptions claimed, but their distribution is independent of this. The prevalence of autism does not depend on racial ancestry [35].

Autism seems to occur in about 60 children, per 10,000 and specifically under the age of 8 , while $10-20$ of these 60 children are closely associated with pervasive developmental disorders. These are data that do not concern a single country but a Global Level [36]. Also, boys are 3 - 4 times more vulnerable to autistic disorders than girls. Regarding the cases of twins, out of 100, 2 to 5 are observed with ASD [36]. Of course, not all cases of people with autistic disorders are considered the same, as there are differences between them such as the mental level, as in a percentage of it $(60 \%-70 \%)$, there are problems of mental retardation, in contrast to a percentage $(40 \%-30 \%)$ where the mental level is at a normal degree. However, there is a small percentage $(10 \%-20 \%)$ where the IQ is above the normal level [37].

Autistic disorders have not been studied as a phenomenon by experts in our country as much as they should. During the last decade, in the years 2003-2004, a survey was conducted and the results were as follows: In Primary Education, in general schools, were enrolled, about 550 students with autistic disorders, which means that 3\% of the total All students in Primary Education were students with 
autistic disorders. Five years later, a survey was conducted at a Diagnostic Center, which displays educational, family and developmental data for Greece. Specifically, out of a total of 2665 children aged 4 to 14, 91 were diagnosed with various forms of autism and different levels of intelligence, which means (3.4\%) of the total, while the cases of boys were more than those of girls and the average age was 6 years of age.

As for older data, specific data from the previous decade, according to the American Centers for Disease Control and Prevention, at the age of about 8 years, one in 70 children developed autism [38]. According to studies conducted in the USA, in fact, autistic disorders are not related to social data, while DNA is not the only factor in the development of autism. However, even in the US, the cases of boys with ASD are much higher compared to the cases of girls [39]. According to the most recent research on autistic disorders, the results are as follows: a minimum percentage, $0.6 \%-0.7 \%$ of the general population, worldwide, is located in the range of ADHD. Of this total, $0.2 \%$ is diagnosed exclusively with ASD, while 0.02 with Asperger Syndrome and 0.3 with other ASD diseases [38]. In Greece, no research has been done on the epidemiology of autism, but it is assumed that the number is proportional to the general population of the country.

The symptoms of autism can vary in intensity and appearance, as well as in the behavior of a person with autism, certain specific characteristics can be observed, such as difficulties in the correct development of oral speech [40]. Significant deficiencies are observed in imitation, attention and play. Children with Autism Spectrum Disorder have disabilities in imitation of body movements, oral cavity and facial expressions [40].

Some people experience hoarseness, some others have difficulty with articulation, syntax, temperament in general of oral speech. In addition, the constant repetitions of the non-narrative ability, the tone and the tone of the voice remain at the same degree without alternations. The greatest difficulties in their speech are located in the factual aspects of language development, they appear as quantitative and qualitative deficiencies in written as well as in oral speech [40]. In most cases, when an adult tries to develop a dialogue with a child with autism, you consider it a very difficult achievement because the topics to be discussed revolve around the issues that concern the child, while there is no patience on the part of the child to express his point of view. The problem is also found in the child's difficulty in understanding expressions with humor or, respectively, in a spirit of irony, while the problem is also found in metaphorical expressions. In short, most children with ASD find it difficult to monitor fluctuations in oral speech [40].

Regarding the degree of socialization, for the largest number of children with ASD, it is located to a very small degree, as they do not want eye contact or physical contact [1]. Creating a friendship between a child with autism and a normal one is considered a difficult task because of the aggressive or abnormal 
behavior of these children. Apart from aggressive acts, from a child with autism, there may be a constant apathy for everything, but you may also notice great sensitivity. In other words, you notice a non-uniformity in the manifestation of emotions, but also an irregularity. In fact, sometimes a child with autistic disorders is "lost" mentally and has the feeling that he is somewhere else or even daydreaming or having reactions to attending classes [1]. However, there are some positive elements in some children with autistic disorders, as long as you do not consider their situation aggravated, such as the element of participating in group games, ambitious behavior giving help to others, the effort to study [1].

The Theory of Mind concerns the ability of each individual to perceive and attribute mental states to himself and others [41]. Specifically, to perceive and impart knowledge, beliefs, desires, additions, emotions, movements. This is the most important human ability in order to develop a degree of socialization [41].

The Theory of Mind has been studied as an important dimension of social cognition, which is necessary for the development of communication between people and the creation of social relationships [41]. In this context, the ability to attribute mental states to others enables us to deceive other people, to hide important information, to keep secrets, to avoid the truth, and to recognize these strategies when used by someone else. But according to another study, the Theory of Mind consists of a kind of metacognitive knowledge, as it concerns knowledge related to the mental states of self and others [41].

The Theory of Mind also functions as a predictor of reports of victimization and the manifestation of aggressive behaviors, bullying behaviors towards weaker people, while it is directly related to the concept of victimization or otherwise of bullying. According to Olweus [42], you use the term victimization to mean that some children consider themselves stronger than other children, thus targeting the weakest children and displaying aggressive behaviors, either in the form of physical violence or in the form of psychological, verbal violence.

Thus, this developmental delay in social knowledge deprives children with autism of the ability to understand the intentions and behaviors of other people [43]. The ability to recognize faces, you consider a very key factor for the development of social and interpersonal relationships, as children with autism disorders to a high degree, sometimes have difficulty, even in recognizing familiar people. Interventions for education in the recognition of emotions should initially focus on the most distinct emotions along with facial expressions such as joy, sadness, surprise, anger, denial [44]. Children with autism, while at normal levels should understand some basic facts such as their own needs, the expressions of others, try to develop a dialogue with their loved ones. On the contrary, children with autistic disorders do not perceive these data, resulting in negative behavior such as egocentrism, isolation, irritability, anger [44].

The goal of integrating Information and Communication Technologies in Special Education is to strengthen independence, improve the degree of socialization and equal opportunities in information for all students, including stu- 
dents with special educational needs, in order to integrate into society [45]. This is a difficult achievement, especially for mainstream schools, because financial resources are needed for the supply of technological equipment and even with special computers and equipment, for hiring special educators and therapists and for remodeling some areas of the school.

The vast majority of students with disabilities, in fact, are deprived of the right to free education in a general school and equal opportunities in education [36]. By equal opportunities, you mean providing support and assistance to all children in general school. The current reality in the field of Special Education in our country feeds the difference and abandonment and leads to marginalization, causing negative effects on development and social integration [36].

From the use of technological equipment by people with autistic disorders, many advantages arise such as the development of the senses, the improvement of written and oral speech, the familiarity with mistakes, the control of movements, the self-concentration [45].

The use of technological means for the education and support of students with autistic disorders, is considered a factor for the interest of special educators and researchers for the advanced possibilities and specialized adaptations of these technological means to the special needs of students. The possibilities provided by modern computers, but also by system software applications, provide many facilities to people with autism. According to a recent study, the technological means aimed at children with autistic disorders, are perfectly adapted to the needs of these children, while they are considered a driving force for the development of the degree of socialization of children but also for improving their spiritual and mental level. In addition, the help of these advanced technological means, you consider valuable in workplaces with adults with ASD.

A previous chapter mentions some characteristics of people with autistic disorders such as hoarseness, abnormal eye contact, difficulty speaking, isolation, excessive mobility and aggressive behaviors. So in improving these difficulties that not only the patient but also all the other members of the family, as well as the people around whom he is surrounded daily (e.g. classmates, teachers, therapists), contribute to advanced technological means. Of course only with programs that handle healthy people, there would be no positive results, so the use of multimedia such as video games, educational videos, video games, are considered very helpful tools, especially to reduce aggressive attitudes and excessive traffic [46].

The use of web-based environments is also of particular interest, as browsers are considered the appropriate tool for a wide range of tools and applications and have an increasing impact on the learning and teaching process [47]. According to a recent study [48] observe increased mobilization and interaction of children with autism, by the use of an enriched with multimedia platform to fully customizable content and format which is friendly to users. Encouraging results from the use of an online platform on the acquisition of skills by adoles- 
cents with ASD have also been reported to be useful for their vocational rehabilitation [45].

Thanks to the rapid development of artificial intelligence, the usefulness of robotics in the diagnosis, treatment and education of people with ASD has begun to be explored. You consider robotics to be an ally that plays a catalytic role in healing, in increasing the degree of socialization and in mediating for the development and improvement of family, social, personal relationships [49]. Robotic interventions in people with autism target the following behaviors: 1) imitation, 2) non-distraction, 3) sequence of switching, 4) recognition of emotions and expressions, 5) initiation of interaction and 6) the ternary interaction [50].

The virtual reality presented through the technological means, is considered a very helpful factor for the improvement of the quality of life of the students with ASD, for the improvement of their behaviors and for the improvement of the spiritual-mental-mental level. But you do not consider it enough, because you also require the cooperation between the parents, the special educators and the special therapists.

The use of technological means by students with autistic disorders is influenced by financial resources, as well as by all members of a school community [51]. Teachers are divided into certain categories such as those who avoid learning the technological means and their familiarity with computers, those who integrate the use of computers in their lesson and adapt only to the needs of the lesson (such as supervising computer tasks during the course or assigning tasks to a computer at home) and finally those who are constantly learning new programs, new commands and new possibilities offered by new technological means [51]. From the teachers belonging to the last category, additional help is given to the students, while they are constantly looking for ways, so that the use by students with autistic disorders, becomes easier as it is connected in various ways with the use of technological means (e.g. with arithmetic games so that children can improve their STEPS or word games to improve his spoken word or even by electronic storytelling, so that children can focus on it) [51].

Data from the international literature of the last twenty years show that the views and attitudes of teachers around ICT differ. In terms of the demographic characteristics of special educators, women teachers seem to make less use of the opportunities provided by technology tools in teaching and to feel less confident about their integration. In the age range, teachers with an average experience of over 10 years, use more technologies for teaching lessons but also for their work at home. On the contrary, teachers with professional experience over 20 years, as well as teachers with professional experience under 5 years, do not prefer the use of technological means for their educational work [52].

\section{Research Methodology}

The purpose of this study is to conduct results on the behaviors of children with autistic disorders in the mainstream school through the views of special educa- 
tors. Behaviors such as: their willingness to study at home, communication between teachers and students, hoarseness and distraction, aggressive behavior, the low degree of socialization of children, the degree of socialization and how these children relate to other children and whether they are affected by various stimuli and differences in the surrounding area.

Also, the purpose of the research is to explore the views of special educators on how important it is to have experts such as child psychologists, gymnasts and what advice they give to parents to make the relationship between family members as smooth as possible. In addition, the purpose is to evaluate the views of special educators, i.e. to what extent they agree or disagree, with burnout. Finally, the purpose is the degree of importance judged by the educators, certain elements such as inclusion in the school curriculum, the prevention of aggressive behaviors.

A research case is the contribution to the recording of the psychological strain and professional exhaustion of the teachers in mainstream schools, where there are children with autism, of the difficulties faced by the students themselves and the teachers in the school environment in ways of treatment that are constantly tested and of the usefulness of working with specialist therapists to facilitate the work of educators and to properly treat students with ASD.

One of the reasons that pushed the researcher to find information not only in books but also through the internet is the abundance of sources and the ability to process a variety of information, which cannot be reproduced in any library, as well as having access to print media.

The present research was conducted from 10/02/2021 to 10/03/2021. The sample selected was a sample of crisis as the questionnaire is addressed exclusively to special educators who treat students with autistic disorders and specifically in public and not private schools.

The research tool that will be used in the present research is a structured questionnaire that is easily analyzed and it is understandable that the presence of the researcher is not necessary, because it can be completed without his help [53]. The questionnaire presents a series of questions that the participant is asked to answer and respond to in any way you ask each time [53]. In the questionnaires you notice a clear order and structure of the questions to which the participant is asked to answer while the form of the questions contained in them is open type. The questionnaire was selected for the purpose of the research as the questions that were created are specific and concern the inclusion of children with ASD in the general school. That is, the questions have a series and interact with each other in order for the results to answer the research questions that you ask the researcher to answer after the end of the research [53].

The material used in the research is a comprehensive and specialized questionnaire in the form of Google Forms, with 15 total questions of which four questions correspond to the demographic data of the participants, five are multiple choice that participants can choose a single answer and multiple option that 
allows participants to choose more than one answer, two Likert Scale questions with answers: strongly disagree, disagree, neither agree nor disagree, agree, strongly agree, a Thurstone Scale question with answers: not at all important, minimal, moderate degree, very, very much, a hierarchical question from 1 to 5 and a probability question with answers: definitely not, probably not, probably, probably yes, definitely yes.

Also, the Laze questionnaire [54] was used, which concerns the inclusion of children with autism in the mainstream school in a regular class and concerned the general and special educators. This tool consists of 28 questions related to the integration of children with special educational needs in the mainstream school. His questions were categorized into three main areas: the knowledge and perceptions of teachers about autism spectrum disorder, the perceptions and attitudes of teachers about the co-education of children with ASD with children with normal development as well as the educational practices that which promote the integration of students with autism in the mainstream school [54].

The theoretical approach to the topic was carried out through a search for information on the Internet and specifically in e-books, published articles, university papers, past research on autistic disorders in children and their inclusion in mainstream school.

The research being conducted in the present work is quantitative and was chosen because questionnaires were used and the purpose is to investigate the subject as clearly as possible in order to delve as deeply as possible into it. Through quantitative research the results for the research are characterized by validity. Quantitative research aims to convert all data into statistical results so that they can be counted accurately and accurately. Quantitative data give a specific sample number, in order to calculate the level of accuracy and the level of probability in order to properly investigate the sample [53]. The researcher chose the quantitative methodological approach to collect objective data on the phenomenon of her study of autistic disorders in children [55] [56] [57]. Each research will meet the criteria of validity and reliability in order for the researcher to be able to claim that his findings can be generalized [58].

Characteristics related to children's autistic disorders are engaging in repetitive activities and stereotyped movements, reacting to changes and stimuli in their environment. The views of most teachers on the inclusive education of children with ASD in mainstream education classes, agree that it can be achieved and especially if there is more support from the state such as the employment of specialist therapists [17]. The views of all teachers were in line with the fact that the family-school relationship is quite important in the smooth integration as well as in the development of children with autism as well as the smooth relationships between all family members help in socialization of the child [4].

The usual result in students with autism is low learning performance but also no improvement in their psychological state [27], disorders in the development of oral speech. Echolalia, the zero or incomplete development of oral speech, 
disorders of the intensity, frequency and rhythm of speech, the different meaning in expressions and words [27], unusual vocabulary for age and social group, a tendency to talk about only specific issues, which belong to the limited interests of the child [27], the non-participation in group games and in group actions in general, the avoidance of developing a dialogue with any other person, the ignorance of the rules of behavior in some places and the isolation [27].

Children with ASD in the field of social development present difficulties both in interpersonal relationships with their peers and in their social transactions [6]. The abnormal function of movements and the refusal to engage in learning activities [27], the important role played by the experience of the educator in handling students with such disabilities, but also the lack of special knowledge to a large extent are only some examples. Therefore, it is prudent for the pedagogical character of the teacher to prevail and for his knowledge and contagion to follow [59]. Insufficient information of parents with children with autistic disorders but also the information of all citizens should be matter, because these children are a part of society. Such initiatives should be carried out in collaboration with private and state bodies in order to be organized [17]. The advice given to these parents is more from the educators themselves than from another body. The economic data of the country are not favorable with the result that many parents are not given the opportunity to visit a child psychologist or a similar therapist and rely on the views and advice of educators [17]. Among the causes of swelling of the problem plays a catalytic role and the way the mother treats the child from infancy [60]. Opinions about whether a child is born or becomes autistic differ as many researchers claim that it occurs while others argue that it is born with autistic disorders [60]. In general, the behavior of the parents plays a very important role i.e. if they help the child, if they spend time with him and do activities that are not related to learning activities.

According to Ouzouni and Nakakis [61] validity refers to whether any measuring instrument claims to measure what it measures, in contrast to the reliability of the measurement tool used in successive measurements [62]. More specifically in terms of reliability, researchers should examine the factors of whether the measurement tool they will use in practice is stable and valid [62]. In order for a research tool to be considered reliable, it must be small when the measurement is repeated under similar or quite similar conditions and the variability of its results is small [61]. In particular, a measurement tool to be valid must be used several times successfully in a population where it has been designed research [62]. More specifically, the validity and reliability of measuring instruments is crucial for the security of good research results [61]. In the present study there will be a sufficient sample size of one hundred special education teachers in order to ensure the performance of a reliable factor analysis and both validity and reliability will be ensured by using the questionnaires drawn from the literature [63].

The research will be conducted with respect to the spiritual integrity and life 
of each person as it will respect the academic truth. The main concern of the research is the preservation of the health of the participants, both mental and physical health and the protection of their individual rights and freedoms. Above all, however, the research is based on the conscious consent of the participants, on the individual's right to be free and to live democratically [53]. All research of a pedagogical nature is carried out with information and written consent from the participants so that there are no possible risks [53]. Participants have the right to leave at any time, even if they have signed their consent. However, participants are assured that the contact information of the researcher is available in case any question about the research is needed. The researcher is willing to answer the questions of his participants. The participants have the right to refuse, i.e. not to give their consent, but even if they have signed, they can leave at any time and not be present during the research [64]. The anonymity of the participants in the research is ensured as the personal data of the participants will not be disclosed because they will be encrypted and will not appear anywhere. The researcher will protect the participants' right to privacy and their personal details will not be disclosed publicly [53].

In the present research, all the ethical issues and ethical principles that govern a research were observed. In particular, complete confidentiality was maintained regarding the information concerning the participants and the security of the relevant material was maintained, while all participants were informed that their personal data will not be used. The results were analyzed by the computer and used exclusively for the purposes of this research and exclusively by the researcher with a questionnaire in the form of Google Form.

In conclusion, scientists have been busy and have studied autism extensively. In the present study, the researcher will find out whether the inclusion of children with autism spectrum disorder in the mainstream school can help according to the views of teachers with special education for autism.

There is no risk with the completion of this questionnaire for the participants while there is no particular reason for medical care at the end of the completion. In the present survey, participants will be informed through an information letter and will only participate if they have conscientiously consented. At the same time, it should be understood that the consent of the participants is not decisive because they can leave the survey at any time they wish. To ensure conscious consent, participants will be given a consent form.

Before the start of the research, the participants will be informed about their rights and obligations but also about the exact content of the research as a whole, giving the researcher specific examples of questions. In particular, accurate information will be provided to the participants regarding the purpose of the research, the duration and the procedures of which you will consist. Once the survey is completed and the results are recorded, the data collected from the questionnaires will be stored in electronic files. Only the researcher will have access to these files for the purpose of preserving and anonymizing the data of the par- 
ticipants.

Due to the fact that the participants in the research work with children, without the children participating, of course, the researcher showed respect for all the rules and processed the demographic characteristics in secret without leaking. Immediately after the completion of the research, the stored personal data of the participants will be deleted in order to comply with the code of ethics and ethics.

\section{Results}

This chapter presents the results of the questionnaires (265 in total) that emerged from the descriptive statistical analysis of the data using the statistical program SPSS Statistics.

The analysis of the aggregate data of the questionnaires begins with the reference of the demographic data that accompany this research. These items are then displayed in a summary table (Table 1).

Of the total of 256 Special Educators who participated in the research, the vast majority with a percentage $(98.9 \%)$ were female $(n=262)$ and only $(1.1 \%)$ male $(n=3)$. Regarding the age of the participants, the largest percentage $(39.2 \%)$ ( $n$ $=104)$, ranges between the ages of 25 and 30 years, while a smaller percentage $(26.8 \%)(n=71)$, ranges between the ages of 31 and 36 years. A slightly smaller percentage of participants $(26.4 \%)(n=71)$, are found in the age range, 37 to 45 years. In a smaller percentage of its class $(6.4 \%)(n=17)$, there are special educators in the age range between 46 and 54 years. The educational level of most of the people who took part in the research, $(n=203)(76.6 \%)$, are graduates of Postgraduate Studies, while a much smaller number of people $(n=55)(20.8 \%)$ are graduates of Higher Education.

Table 1. Results.

\begin{tabular}{|c|c|c|c|c|c|c|}
\hline \multicolumn{7}{|c|}{ ANOVA } \\
\hline & & Sum of Squares & $\mathrm{df}$ & Mean Square & $\mathrm{F}$ & Sig. \\
\hline \multirow{3}{*}{$\begin{array}{l}\text { The gender of the } \\
\text { participants }\end{array}$} & Between Groups & 0.067 & 4 & 0.017 & 1.509 & 0.200 \\
\hline & Within Groups & 2.899 & 260 & 0.011 & & \\
\hline & Total & 2.966 & 264 & & & \\
\hline \multirow{3}{*}{$\begin{array}{l}\text { The age of the } \\
\text { participants }\end{array}$} & Between Groups & 2.796 & 4 & 0.699 & 0.684 & 0.604 \\
\hline & Within Groups & 265.898 & 260 & 1.023 & & \\
\hline & Total & 268.694 & 264 & & & \\
\hline \multirow{3}{*}{$\begin{array}{l}\text { The educational level } \\
\text { of the participants }\end{array}$} & Between Groups & 0.444 & 4 & 0.111 & 0.545 & 0.703 \\
\hline & Within Groups & 52.862 & 260 & 0.203 & & \\
\hline & Total & 53.306 & 264 & & & \\
\hline
\end{tabular}


The work experience of most of the people who took part in the research, have the least possible experience, 1 to 5 years to be exact $(n=134)(50.6 \%)$. In the next scale of work experience, 6 to 10 years, we notice a much smaller percentage of participants $(19.6 \%)(\mathrm{n}=52)$. With more work experience, 11 to 15 years, there are $(n=47)$ participants $(17.7 \%)$ and with work experience 16 to 20 years, we observe a much smaller number of participants $(n=18)(6.8 \%)$. With even greater work experience, over 20 years, we notice a much smaller percentage of participants 95.3\%) ( $\mathrm{n}=14)$.

On the question of whether the professional exhaustion of special educators is affected by the effectiveness of the educational work and the emotional intelligence of students with ASD, agrees the 52.8\%. From a smaller percentage of participants $(24.5 \%)$, a complete view is not expressed, in fact a neutral attitude is maintained, while from a smaller percentage, of the order of $13.2 \%$, we notice an absolute agreement that the burnout of special educators is affected by the effectiveness of the educational work and emotional intelligence.

\section{2nd RESEARCH QUESTION}

Degree of importance of the integration program, will for study, communication between students (correlation method).

According to the following table, the degree of importance of an integration program for students with autistic disorders in the mainstrem school is more related to the development of communication between teachers and students, with (i.e. -0.145$)$ and with a loss of only $(-0.0018)$. The degree of importance of the will to study, of students with autism, in the mainstream school, is more associated with the development of communication between teachers and students, with (i.e. -0.145$)$ and with a loss of only $(-0.004)$. The degree of importance of the communication that develops between teachers and students, is more related to the degree of importance of the students' will to study with (i.e. -0.145 ) and loss $(-0.003)$.

\section{3rd RESEARCH QUESTION}

\section{The common emotions of students with ASD}

Some of the most common emotions of students with ASD are apathy, excessive reaction to any stimulus, hoarseness and distraction. For these data, the special educators were asked and according to the highest percentage of participants $(38.3 \%)(\mathrm{n}=102)$ the excessive reaction to any stimulus is the most common emotion that occurs in students with autistic disorders, while with one small difference, apathy is an emotion that you also notice in students with ASD, according to $(35.7 \%)(n=95)$ of the participants. From a much smaller percentage of special educators who participated in the research, $(16.1 \%)(n=43)$ to be exact.

\section{RESEARCH QUESTION 4}

Students with ASD include a general school (frequency descriptives method)

According to half, almost participants (50.9\%) to be precise, it is considered certain that a child with autistic disorders can enroll in mainstream school, while according to $3.4 \%$ this is not possible to happen. However, there is a percentage 
of $45.5 \%$ who are in favor of the view that it's considered possible for a student with autism to be able to enroll in a mainstream school.

\section{RESEARCH QUESTION 5}

If you consider the existence of a special trainer in the general school necessary when there are students with ASD (descrict method)

According to the highest percentage of participants (81.9\%), the presence of a specialist therapist in a school, when there are students with autistic disorders, is considered very necessary. While according to a much smaller percentage of participants (16.6\%), the presence of the special educator to support students with ASD, is considered very important.

\section{RESEARCH QUESTION 6}

Degree of importance of a special pediatrician, teacher, general in general schools for supporting students with students

The following table shows the Average of each element (Mean), which is not an integer but a decimal. So when in some element (Mean is 4.5) then the score of the element is not considered 4 but 5. On the contrary, when (Mean is 4.2), the score of the element is 4 . Therefore, the correct score, always depends on the first digit followed by the party. The degree of importance of having a child psychologist in a general school, where there are also students with autistic disorders, is characterized as quite high (Average 4.11), as well as the degree of importance of having a special gymnast (Average 4.23). As for the degree of importance of the special educator in a general school where there are children with autistic disorders, it reaches the highest degree (Average 4.55).

\section{RESEARCH QUESTION 7}

Presence of students with ASD to satisfaction of teachers (descriptive statistics frequency method)

\section{RESEARCH QUESTION 8}

Prevention of discoveries and aggressive behavior of students by teachers-cooperation with people of other specifications

According to the statements of $100 \%$ of the participants, the collaboration with people of different specialties within the school community, is necessary and can help students with autism and the educational work itself. According to 86.7\% $(\mathrm{n}=230)$ teachers sometimes have the ability to deal with the difficult behaviors of students with autism. In stark contrast to $9 \%(n=24)$, which always happens and to $(4.2)(\mathrm{n}=11)$ which does not happen that teachers can deal with difficult behaviors of students with ASD. The smallest percentage of participants $(1.5 \%)(n=4)$, certainly do not have the skills to cope the aggressive behaviors of students with ASD, while 5.7\% $(\mathrm{n}=15)$ probably do not have the skills. A higher percentage of participants $(32.8 \%)(n=87)$ consider it possible to be able to deal with the aggressive behaviors of students with ASD and the highest percentage $(56.4 \%)(\mathrm{n}=150)$ can deal with them.

\section{RESEARCH QUESTION 9}

Teacher advice to parents with children with ASD (descriptive statistics fre- 
quency method)

As shown in the following graph, according to a strong number of people who participated in the research $(n=139)(52.7 \%)$, sessions with the psychologist and with the participation of the child, are considered an auxiliary tool. From a much smaller number of participants $(n=23)(8.7 \%)$ making frequent visits between parents and teachers is also a useful tip when there is a child with autism in the family. Psychological support for children to feel equal is a piece of advice also provided by $(\mathrm{n}=27)$ and $(8.7 \%)$, while extracurricular activities with the child consist of a larger number of participants $(n=29)(11 \%)$. The cooperation between parents and people of different specialties, consists of a high number of participants $(n=50)(18.9 \%)$.

\section{Conclusions}

According to the bibliographic reports, the main elements of children with ASD are the characteristic peculiarity of the gaze and specifically the absence of eye contact and the fact that they perceive things only with a sideways gaze and never directly [22]. Moreover, early childhood education which is of major importance and is associated with a better start to students' schooling, can assist them to cope the effects of social disadvantage [65].

According to the literature, you notice a strong denial of children with autism, in terms of learning and cooperation with educators, as well as a negative relationship with other family members and classmates [26]. Also, there are difficulties in the correct development of oral speech and significant deficiencies are observed in imitation, attention and play [40]. A fact, which agrees with a high percentage of survey participants, of course not the highest but a percentage of more than $50 \%$.

According to the bibliographic sources, in children with autism, you notice aversion to family members who care for them and a high degree of isolation, hoarseness, hyperactivity, distraction [27]. According to research, hoarseness and distraction are not common in children with ASD, as opposed to apathy and excessive reaction to any stimulus.

By offering students with autistic disorders, solutions such as the special educator, the child psychologist, access to technological means, the result is an increase in their degree of socialization, while the feeling of diversity and the solution of isolation are eliminated [7] [8]. Information that is in line with the results of the research, as according to (82\%) of the participants, you consider the presence of specialist therapists very important and especially the presence of a special educator.

According to the theory, when an adult tries to develop a dialogue with a child with autism, you consider it a very difficult achievement because the topics to be discussed revolve around the issues that concern the child, while there is no patience on the part of the child to express his opinion [40]. The fact that the highest percentage of participants agrees is very important, as the dialogue between 
adults and children with autism is a very crucial element for their inclusion in the mainstream school.

The vast majority of students with disabilities, in fact, are deprived of the right to free education in a mainstream school and equal opportunities in education [36]. Theory, which agrees with the research, as most participants, believes that a student with autistic disorders can join the mainstream school.

From the use of technological equipment by people with autistic disorders, many advantages arise such as the development of the senses, the improvement of written and oral speech, the familiarity with mistakes, the control of movements, the self-concentration [45].

\section{Acknowledgements}

This study would not have been possible without the contribution of numerous people. I would like to thank the educational staff who took part in the research.

\section{Conflicts of Interest}

The author declares no conflicts of interest.

\section{References}

[1] Gena, A. (2007) Theory and Practice of Behavior Analysis. Gutenberg, Athens.

[2] European Commission (2000) Key Numbers of Education in Europe. http://www.eurydice.org

[3] Besila-Vika, E. (2010) Local Government. Vol. 1, 3rd Edition, London.

[4] Exarchou, E. (2020) Sciences of Education: Psychology in Education and Special Education Results.

[5] Loveland, K. and Kotoski, B. (2005) The School Age Child with an Autistic Spectrum Disorder. In: Volkmar, F.R., Paul, R., Klin, A. and Cohen, D., Eds., Handbook of Autism and Pervasive Development Disorders. Diagnosis, Development, Neurology and Behavior, Vol. 1, John Wiley \& Sons, Inc., Hoboken, 247-287. https://doi.org/10.1002/9780470939345.ch9

[6] Nova, Ch. (2016) A Comparative Approach to the Aggressive Behavior of Children with Autism in School Age. Proceedings of the 5 th Panhellenic Conference of Educational Sciences, Athens, 19-21 June 2015, 1-11. https://eproceedings.epublishing.ekt.gr/index.php/edusc/article/viewFile/244/209

[7] Christoforaki, K. (2005) The Integration of Children with Disabilities in the School Process. Proceedings of the Access Conference, Ioannina, 1-5 June 2005, 1-19.

[8] Gerodiakos, K. (2005) New Technologies and Motor Disability. Proceedings of the Access Conference, Ioannina, 1-5 June 2005, 28-36.

[9] Cooper, J., Heron, T. and Heward, W.L. (2007) Applied Behavior Analysis. Pearson Merrill Prentice Hall, Upper Saddle River.

[10] Mastrogiannis, A. and Xanthopoulou, E. (2015) Management and Treatment of Autism through Parallel Support Procedures. Proceedings of the 5 th Panhellenic Conference of Educational Sciences, Athens, 19-21 June 2015, 111-132. https://eproceedings.epublishing.ekt.gr/index.php/edusc/article/view/160/126

[11] Tsiantis, I. (2001) Mental Health of the Child and the Family. Issue B, Kastaniotis 
Editions.

[12] Dale, N. (2000) Ways of Working with Families of Children with Special Needs. Athena Publishing, Athens.

[13] Tsimpidaki, A. (2007) Child with Special Needs, Family and School. A Relationship in Interaction. Atrapos, Athens.

[14] Britain, S. and Liber, O. (2004) A Framework for Pedagogical Evaluation of Virtual Learning Environments. hal-00696234.

[15] Law 3699/2008 (Government Gazette 199-A-2-10-2008) Special Education and Training of Persons with Disabilities or Special Educational Needs. http://www.pi-schools.gr

[16] Avramidis, H. and Dialektaki, K. (2010) Chapter 3. Education of Children with Special Needs. In: Changing Teachers' Attitudes towards Inclusion: From the Ideology of Authority to the Authentic Application of Inclusive Education, Pedio, Athens, 216.

[17] Tsitlakidou, P. and Mourelatou, A. (2012) Autism, Inclusion in a Regular School, Therapeutic Goals and Adaptation of the Primary School Textbook for an Autistic Child. Epirus Technological Educational Institute, Department of Speech Therapy.

[18] Mayes, D.S. and Calhoun, L.S. (2003) Relationship between Asperser Syndrome and High-Functioning Autism. In: Prior, M., Ed., Learning and Behavior Problems in Aspersers Syndrome, Guilford Press, New York, 15-34.

[19] Kanner, L. (1943) Autistic Disturbances of Affective Contact. Nervous Child, 2, 217-250.

[20] Kakouros, E. and Manidaki, K. (2006) Child \& Adolescent Psychopathology Developmental Approach. Athena, Athens.

[21] Bania, T.A., Antoniou, A.S., Theodoritsi, M., Theodoritsi, I., Charitaki, G. and Billis, E. (2021) The Interaction with Disabled Persons Scale: Translation and Cross-Cultural Validation into Greek. Disability and Rehabilitation, 43, 988-995. https://doi.org/10.1080/09638288.2019.1643420

[22] Heward, W., Cooper J. and Heron, T. (2007) Applied Behavior Analysis. Pearson Merrill Hall, Upper Saddle River.

[23] Antoniou, A.S., Geralexis, I. and Charitaki, G. (2017) Special Educators' Teaching Self-Efficacy Determination: A Quantitative Approach. Psychology, 8, 1642-1656. https://doi.org/10.4236/psych.2017.811108

[24] Varvogli, L. (2006) The Diagnosis of Autism: A Practical Guide. Kastanioti, Athens, 32-33.

[25] Vogiatzi, X.A., Charitaki, G. and Kourkoutas, E. (2021) Assessing Psychometric Properties of the Sentiments, Attitudes and Concerns about Inclusive Education Scale in a Greek-Speaking Sample of In-Service Teachers. Technology, Knowledge and Learning, 1-17. https://doi.org/10.1007/s10758-021-09554-x

[26] Polychronopoulou, S. (2017) Children and Adolescents with Special Needs and Possibilities. Topos, Athens, 114.

[27] Tentomas, K. (2007) Exotic Children, Domestic Children. 28.

[28] Maidoni, V. and Tziatziou, A. (2016) The Role of the Speech Therapist in the Spectrum of Autism in Children. Thesis, Department of Speech Therapy Technological Educational Institute of Epirus.

http://apothetirio.teiep.gr/xmlui/bitstream/handle/123456789/5166/\%ce\%9c\%

[29] Happe, F.G. and Frith U. (Eds.) (2010) Autism and Talent. Oxford University Press, Oxford. 
[30] American Psychiatric Association (2013) Diagnostic and Statistical Manual of Mental Disorders. 5th Edition Revised, American Psychiatric Association Publishing, Washington DC. https://doi.org/10.1176/appi.books.9780890425596

[31] Staipoltzi, A., Stylianaki, E. and Stavrinou, E. (2020) Parents' Perceptions and Opinions about the Vaccine: Pilot Study with Parents' Health Professionals and Parents' Non-Health Professionals. Hellenic Journal of Nursing Science, 13, 60-71. https://doi.org/10.24283/hjns.202046

[32] Gatzoya, Th. (2018) Theatrical Play in Students with Mild to Moderate Mental Retardation. Pedio, Athens.

[33] Charitaki, G., Soulis, S.G. and Tyropoli, R. (2019) Academic Self-Regulation in Autism Spectrum Disorder: A Principal Components Analysis. International Journal of Disability, Development and Education, 68, 26-45.

https://doi.org/10.1080/1034912X.2019.1640353

[34] Tzivinikou, S., Charitaki, G. and Kagkara, D. (2020) Distance Education Attitudes (DEAS) during Covid-19 Crisis: Factor Structure, Reliability and Construct Validity of the Brief DEA Scale in Greek-Speaking SEND Teachers. Technology, Knowledge and Learning, 26, 461-479. https://doi.org/10.1007/s10758-020-09483-1

[35] Kochila, S.A. (2016) Autistic Characteristics in Young Adults and Their Relationship to Obsessive-Compulsive Symptoms. Pedio, Athens.

[36] Mentza, S. (2016) Views of Parents of Children with Autism Spectrum Disorders Regarding the School and Social Integration of Their Children. Thesis, University of Western Macedonia, Kozani.

[37] Wood, A.R., Esko, T., Yang, J., Vedantam, S., Pers, T.H., Gustafsson, S., Lichtner, P., et al. (2014) Defining the Role of Common Variation in the Genomic and Biological Architecture of Adult Human Height. Nature Genetics, 46, 1173-1186. https://doi.org/10.1038/ng.3097

[38] Wittchen, H.U., Jacobi, F., Rehm, J., Gustavsson, A., Svensson, M., Jönsson, B., Steinhausen, H.C., et al. (2011) The Size and Burden of Mental Disorders and Other Disorders of the Brain in Europe 2010. European Neuropsychopharmacology, 21, 655-679. https://doi.org/10.1016/j.euroneuro.2011.07.018

[39] Centers for Disease Control and Prevention (2019) Data and Statistics on Autism Spectrum Disorder. Centers for Disease Control and Prevention, Atlanta. https://www.cdc.gov/ncbddd/autism/data.html

[40] Galanis, S. (2015) The Value of Information under Unawareness. Journal of Economic Theory, 157, 384-396. https://doi.org/10.1016/j.jet.2015.01.015

[41] Misailidi, P. (2010) Children's Metacognition and Theory of Mind: Bridging the Gap. In: Efklides, A. and Misailidi, P., Eds., Trends and Prospects in Metacognition Research, Springer, Boston, 279-291. https://doi.org/10.1007/978-1-4419-6546-2_13

[42] Olweus, D. (2003) A Profile of Bullying at School. Educational Leadership, 60, 12-17.

[43] Varthalami, K. and Karagianni, L. (2017) Autism: From the Theoretical to the Therapeutic Approach. Pedio, Athens.

[44] Hatzipanagis, B. (2010) Autism. Doctoral Thesis, Technological Educational Institute of Epirus, Schools of Health and Welfare Professions, Department of Speech Therapy, Ioannina.

[45] Tsiopela, D. and Tzimogiannis, A. (2018) ICT in the Education of People with Autism Spectrum Disorders: A Literature Review. Science and Technology in Education, 10, 19-35. 
[46] Bania, T., Gianniki, M., Giannakoudi, S. and Charitaki, G., Matzaroglou, C. and Billis, E. (2020) The Interaction with Disabled Persons Scale (IDPS): Evidencing Construct Validity with Factor Analysis and Measurement Invariance in Greek-Speaking Healthcare students. Disability and Rehabilitation. https://doi.org/10.1080/09638288.2020.1850890

[47] Laws, G. and Bishop, D.V. (2003) A Comparison of Language Abilities in Adolescents with Down Syndrome and Children with Specific Language Impairment. Journal of Speech, Language, and Hearing Research, 46, 1324-1339. https://doi.org/10.1044/1092-4388(2003/103)

[48] da Silva, C.A., Fernandes, A.R. and Grohmann, A.P. (2014) Assisting Speech Therapy for Autism Spectrum Disorders with an Augmented Reality Application. Proceedings of the 16th International Conference on Enterprise Information Systems, Lisbon, 27-30 April 2014, 38-45.

[49] Dautenhahn, K. (2003) Roles and Functions of Robots in Human Society: Implications from Research in Autism Therapy. Robotica, 21, 443-452.

https://doi.org/10.1017/S0263574703004922

[50] Cabibihan, J.J., Javed, H., Ang, M. and Aljunied, S.M. (2013) Why Robots? A Survey on the Roles and Benefits of Social Robots in the Therapy of Children with Autism. International Journal of Social Robotics, 5, 593-618. https://doi.org/10.1007/s12369-013-0202-2

[51] Mumtaz, S. (2000) Factors Affecting Teachers' Use of Information and Communications Technology: A Review of the Literature. Journal of Information Technology for Teacher Education, 9, 319-342. https://doi.org/10.1080/14759390000200096

[52] Tzimogiannis, A. and Komis, B. (2004) Attitudes and Perceptions of Secondary School Teachers Regarding the Application of ICT in Their Teaching. Proceedings of the 4th Panhellenic Conference with International Participation "Information and Communication Technologies in Education", Athens, 1-5 August 2004, 165-176.

[53] Cohen, L., Manion, L. and Morrison, K. (2008) Educational Research Methodology. Metaichmio, Athens.

[54] Laze, S. (2019) Knowledge and Perceptions of Teachers of General and Special Education for the Integration of Children with Autism in the Regular Class of the General School. Postgraduate Work. University of Patras, Patras. https://nemertes.lis.upatras.gr/jspui/bitstream/10889/12271/1/\%ce $\% 94 \%$ ce $\% 99 \%$ ce \%a0\%ce\%9b\%ce\%a9\%ce\%9c\%се\%91\%се\%a4\%се\%99\%се\%9a\%ce\%97-\%се\%95\%ce \%a1\%ce\%93\%ce\%91\%ce\%a3\%ce\%99\%се\%91-\%се\%9b\%ce\%ac\%ce\%b6\%ce\%b5\%20 \%ce\%a3\%cf\% $84 \%$ cf\% $85 \%$ ce\%bb\%ce\%b9\%ce\% b1\%ce\%bd\%ce\%ae.pdf

[55] Parahoo, K. (2006) Nursing Research: Principles, Process and Issues. 2nd Edition. Palgrave Macmillan, Houndmills Basingstoke.

[56] Sarantakos, S. (1998) Sampling Procedures. In: Social Research, Palgrave, London. https://doi.org/10.1007/978-1-349-14884-4_6

[57] Mantzoukas, S. (2007) Qualitative Research in Six Easy Steps. Epistemology, Methods and Presentation.

http://openworkshop.pbworks.com/w/file/fetch/64390801/6-bhmata-poiotikh-ereyn a.pdf

[58] Tsiolis, G. (2011) The Relationship between Qualitative and Quantitative Research in the Social Sciences: From the War of "Examples" to Complex Approaches. Topos, Athens.

[59] Zoniou-Sideri, A. (2000) People with Special Needs and Their Integration. Ellinika Grammata, Athens, 27-43. 
[60] Golse, B. (2005) Les précurseurs corporels et comportementaux de l'accès au langage verbal. Neuropsychiatrie de P enfance et de Padolescence, 53, 340-348. https://doi.org/10.1016/j.neurenf.2005.09.022

[61] Ouzouni, Ch. and Nakakis, K. (2011) The Reliability and Validity of Measurement Tools in Quantitative Studies. Nursing, 50, 231-239.

[62] Charitakis, F. (2012) Reconstruction of Teaching Using ICT, Based on the Conceptual Framework of Technological and Pedagogical Knowledge of Content (ICT). Investigation of the Possibility in Teachers of Alexandroupolis. Bachelor's Thesis, Democritus University of Thrace, Xanthi. https://repo.lib.duth.gr/jspui/bitstream/123456789/1356/1/EA90.PDF

[63] Iseris, G. (2016) Statistical Methods of Checking the Validity and Reliability of Questionnaires. The Case of GREECE. International Journal of Language, Translation and Intercultural Communication, 5, 175-189.

https://doi.org/10.12681/ijltic.10665

https://www.researchgate.net/publication/309225596_Statistikes_methodoi_elencho u_enkyrotetas_kai_axiopistias_erotematologion_E_periptose_tou_CiGreece

[64] Antoniou, A.S. (2006) Ethical Requirements and Codes of Ethics against Conducting Research in a Psychological Field. Journal of Philosophy, No. 2, 68-81.

[65] Charitaki, G., Tzivinikou, S., Stefanou, G. and Soulis, S.G. (2020) A Meta-Analytic Synthesis of Early Numeracy Interventions for Low-Performing Young Children. SN Social Sciences, 1, Article No. 105. https://doi.org/10.1007/s43545-021-00094-w 